\title{
La alta sociedad, el mundo de la cultura y la modernización en la Buenos Aires del cambio del siglo XIX al XX
}

\author{
Leandro Losada
}

Facultad de Ciencias Humanas, UNCPBA

En el artículo se abordan las sociabilidades intelectuales y las trayectorias de algunos de los personajes más destacados en estas esferas en la Buenos Aires del novecientos. El propósito central es reflexionar sobre el impacto que los profundos cambios económicos, sociales, políticos y culturales que se produjeron en la Argentina por entonces, entre ellos la profesionalización de las actividades intelectuales, tuvieron sobre el rol central que hasta el fin de siglo había ocupado la alta sociedad tradicional en el campo de la cultura. La hipótesis del artículo es que dichas mutaciones desdibujaron ese papel, y en consecuencia, pertenecer o estar vinculado a la elite tradicional pudo ser un capital relevante pero no ya decisivo para obtener éxito o reconocimiento en el mundo de la cultura.

PALABRAS CLAVE: alta sociedad, cultura, modernización.

The article analyses the intellectual sociabilities and the trajectories of some of the most outstanding figures of this spheres in the Buenos Aires of the turn of the XIX to XX century. The main purpose is to think about the impact of the profound economic, social, political and cultural changes that affect the Argentina in this period, between them the professionalisation of the intellectual activities, over the central role that, until then, had played the traditional high society in the cultural field. The article hypothesis is that these mutations decreased that role, and, therefore, to belong to the traditional elite might be a relevant capital but not a crucial one to obtain success or prestige in the cultural field.

KEYWORDS: high society, culture, modernization.

En el período extendido entre el último cuarto del siglo XIX y las tres primeras décadas del XX, la Argentina sufrió radicales transformaciones políticas, económicas, sociales y culturales, entre las cuales se destacan: la consolidación del Estado Nacional en 1880 y la reforma electoral de 1912 (que sancionó el sufragio secreto, universal y obligatorio para la población masculina adulta, nativa y nacionalizada), la definitiva integración al mercado mundial, la renovación del aparato productivo, comercial y financiero, y un boom exportador que provocó una expansión de la economía prác- 
ticamente ininterrumpida entre el novecientos y el estallido de la Guerra Mundial; la mutación de la sociedad originada por la movilidad social, el crecimiento demográfico y la renovación poblacional generada por una oleada inmigratoria sin parangones en el mundo en lo que hace a su peso relativo en la sociedad receptora. ${ }^{1}$ El hecho de considerar la metamorfosis estructural como un abanico de procesos aceleradores de la modernización del país impidió que los investigadores —en pos de resaltar las rupturas con las etapas anteriores - advirtieran su relación con los sucesos precedentes, de los que, sin duda era continuadora. ${ }^{2}$

Semejantes alteraciones impactaron en la estructura y en la dinámica sociales. Antes, la sociedad porteña había sido bastante permeable y poco estática. Así, entre los protagonistas de la vida nacional del novecientos se contaron individuos que procedían de diversas familias de tardía inserción en la sociedad local, fundadas por inmigrantes radicados durante el XIX, aunque previo al boom de fin de siglo. Un buen ejemplo es Carlos Pellegrini, argentino de primera generación, hijo de un ingeniero saboyano llegado a Buenos Aires en los años 1820, impulsor y presidente del principal club de la alta sociedad porteña del novecientos: el Jockey Club; y una figura central de la política nativa del cambio de siglo, como presidente de la nación entre 1890 y $1892^{3}$.

Aun así, los rasgos generales de la estructura social de los dos primeros tercios del siglo XIX previos a los cambios radicales de fin de siglo podrían representarse en los términos de lo que se ha dado en llamar una estratificación tradicional. Es decir, una masa relativamente indiferenciada de sectores populares, por un lado, y por otro, una minoría conformada por

1 Véase Botana, N.: El orden conservador. La política argentina entre 1880 y 1916, Sudamericana, Buenos Aires, 1994; Botana, N. y Gallo, E.: De la República posible a la República Verdadera, Ariel, Buenos Aires, 1997; Cortés Conde, R.: El progreso argentino. 1880-1914, Sudamericana, Buenos Aires, 1979; Devoto, F.: Historia de la inmigración en la Argentina, Sudamericana, Buenos Aires, 2003.

2 Germani, G.: Política y sociedad en una época de transición. De la sociedad tradicional a la sociedad de masas, Paidós, Buenos Aires, 1962.

3 Véase Gallo, E.: Los nombres del poder. Carlos Pellegrini, FCE, Buenos Aires, 1998. En el terreno económico hubo ejemplos igualmente notables de vertiginosa promoción social, como la familia Santamarina, fundada por un inmigrante español a mediados del siglo XIX, que comenzó como comerciante y transportista de carretas entre la ciudad de Buenos Aires y el interior de la provincia, y llegó a ser, pocos años después, uno de los más importantes terratenientes de la pampa húmeda. Véase Reguera, A.: "Familia, formación de patrimonios y transmisión de la tierra en Argentina. Los Santamarina en Tandil (1840-1930)", en Gelman, J.; Garavaglia, J. C. y Zeberio, B. (comps.): Expansión capitalista y transformaciones regionales. Relaciones sociales y empresas agrarias en la Argentina del siglo XIX, UNICEN-La Colmena, 1999. 
familias cuyos miembros, de orígenes diversos, gravitaban en los lugares decisorios de las diferentes dimensiones de la sociedad. ${ }^{4}$

En cambio, al compás de las mutaciones mencionadas, se fueron delineando, poco a poco, campos con una mayor entidad propia, con lógicas y reglas específicas, ${ }^{5}$ y en ellos, elites cuya composición fue más mixturada por efectos de las alteraciones en la población y de la movilidad social, y en las que el lugar de preeminencia resultó más bien de una consagración y de un reconocimiento obtenidos en la esfera de marras, antes que fruto del origen o de la extracción social. En consecuencia, el peso y la gravitación de la alta sociedad tradicional se atenuaron a lo largo de este período, en tanto que medró el protagonismo de sus integrantes en los espacios decisorios de la sociedad, si bien no se eclipsó de manera absoluta. ${ }^{6}$

En este artículo ilustraremos este proceso haciendo foco en el mundo de la cultura, y más precisamente en las trayectorias y sociabilidades intelectuales. Vale precisar que entendemos la condición de intelectual en un sentido amplio: aquel que, si no vive de, sí al menos vive para las actividades intelectuales, ${ }^{7}$ consideradas además como aquellas que agrupaban tanto a hombres de ciencia y académicos, como a individuos más bien volcados a las disciplinas literarias y artísticas. Estas concepciones se anclan, en buena medida, en los propios rasgos de la realidad: fue frecuente que una misma persona alternara entre todas estas actividades, mientras que, a la vez, la consolidación del mercado como esfera de consagración de la producción cultural y la misma profesionalización, tanto en el mundo académico como en el artístico y el literario — procesos que fueron cobrando forma a lo largo de estos años - hicieron posible, paulatinamente, que al "vivir para" se sumara el "vivir de" ${ }^{8}$ Es importante también dejar en claro

4 Para un modelo de este tipo de estratificación social, véase Germani, Política y sociedad..., págs. 116-126.

5 Seguimos aquí la noción de "campo" planteada por Bourdieu, P,: "Campo intelectual y proyecto creador", en AAVV: Problemas del estructuralismo, Siglo XXI, México, 1967.

6 Nos permitimos remitir aquí a Losada, L.:”¿Oligarquía o elites? Estructura y composición de las clases altas de la ciudad de Buenos Aires entre 1880 y 1930", en HAHR (en prensa, publicación en febrero de 2007).

7 La distinción entre "vivir para" y "vivir de" la tomamos de Weber, M.: Economía y Sociedad, FCE, México, 1992, págs. 1066-1068.

8 Con relación al ámbito académico, véase Buchbinder, P.: Historia de la Facultad de Filosofía y Letras, EUDEBA, Buenos Aires, 1997. Respecto del mundo de las letras, véase Sarlo, B. y Altamirano, C.:'La Argentina del centenario: campo intelectual, vida literaria y temas ideológicos", Ensayos argentinos. De Sarmiento a la vanguardia, CEAL, Buenos Aires, 1983. En el campo de las llamadas profesiones liberales, se destaca el trabajo sobre los médicos de González Leandri, R.: Curar, persuadir, gobernar. La construcción histórica de la profesión médica en Buenos Aires, 1852-1886, Consejo Superior de Investigaciones Científicas- Centro de Estudios Históricos, Madrid, 1999. 
desde un principio que a lo largo de estas páginas haremos referencia a los individuos más cercanos al mundo literario y/o artístico que al académico o científico, y a las entidades y cenáculos más directamente vinculados con el terreno cultural que con el corporativo-profesional.

Entonces, veremos cómo, mediante las características de las sociabilidades intelectuales y de las trayectorias de algunos de los personajes más destacados en estas esferas, se aprecia cómo se desvanece el rol central que hasta el fin de siglo había ocupado la alta sociedad tradicional y sobre ello, la progresiva consolidación de un campo intelectual dotado de una lógica propia o específica, ante lo cual pertenecer o estar vinculado a la elite tradicional podía ser un capital relevante, pero no ya decisivo para obtener éxito o reconocimiento en el mundo de la cultura. De esta manera, nuestro propósito es ofrecer una serie de lineamientos que ayuden a enriquecer la discusión sobre las características y los alcances de la profesionalización de las actividades intelectuales en la Buenos Aires del cambio de siglo, y, en un sentido más amplio, considerar algunas reflexiones que nos permitan evaluar el impacto de las transformaciones globales que recorrieron al conjunto de la sociedad a lo largo de dicho período.

\section{Las sociabilidades intelectuales en el fin de siglo}

Los cenáculos y los círculos intelectuales más destacados que aparecieron en la Buenos Aires del último cuarto del siglo XIX vinieron en buena medida a suplir la ausencia que el Estado acusaba por entonces en lo tocante al incentivo de las artes y de las ciencias - como lo subrayara más de uno en esos mismos años - y a ofrecer espacios de sociabilidad intelectual escasos en la Universidad de Buenos Aires, ganada por un sello orientado a la formación de profesionales liberales, antes que de científicos, académicos o investigadores (una característica duradera que sólo se vería parcialmente atenuada con la creación de la Facultad de Filosofía y Letras en 1896). ${ }^{10}$

9 Véase García Mérou, M.: Recuerdos literarios (1891), CEAL, Buenos Aires, 1982.

10 Halperín Donghi, T.: Historia de la Universidad de Buenos Aires, EUDEBA, Buenos Aires, 1962; Amadeo, J.: La Universidad condicionada. La Universidad de Buenos Aires y su lugar en el proyecto político del siglo XIX, Centro de Investigaciones Educativas, Buenos Aires, 1976; Buchbinder, Historia de la... Vale señalar que a pesar de este perfil "profesionalista", las entidades corporativas profesionales (a excepción de la Asociación Médica, que se remontaba a 1860) aparecieron relativamente 
Esto permite entender que en los círculos intelectuales del fin de siglo convivieran quienes estaban más apegados a las actividades artísticas o literarias y aquellos más vinculados con el campo académico (aunque ambos perfiles distaran de ser mutuamente excluyentes), una convivencia que se reflejó incluso en los nombres de algunos cenáculos, como el Círculo Científico y Literario de los años setenta. ${ }^{11}$ No obstante, el más importante fue el Ateneo de Buenos Aires, creado en 1892. ${ }^{2}$ Esta entidad fue crucial porque estimuló las actividades literarias, plásticas y musicales e incluso alentó su profesionalización, al reunir a individuos vinculados con estas distintas disciplinas. Allí, por ejemplo, se propuso que los medios de prensa pagaran por sus colaboraciones, cuando por entonces sólo lo hacía el diario La Nación. ${ }^{13}$

Otro organismo importante - sobre todo para las letras y la investigación histórica - fue la revista La Biblioteca, creada y dirigida por el francés Paul Groussac entre 1896 y 1898. La figura de Groussac devela que antes de la inmigración masiva del cambio de siglo, el espacio intelectual no estuvo completamente delimitado a los sectores sociales tradicionales, en buena medida a causa de la carencia de los recursos humanos necesarios para ocupar los lugares disponibles. En efecto, a lo largo del tercer cuarto del siglo XIX, Groussac — que había llegado al país en 1848 - construyó una exitosa carrera iniciada en el campo educativo, cuando ingresó como profesor en el Colegio Nacional de la provincia de Tucumán en 1871 donde residió durante once años, llegando a desempeñarse en su Dirección de Enseñanza-, y continuó luego, en 1883, ya en Buenos Aires como Director General de Enseñanza Secundaria. Fue entonces cuando se convirtió en el director de uno de los diarios más importantes de esa década: Sud América, hasta que fue designado al frente de la Biblioteca Nacional

\footnotetext{
tarde. Así, por ejemplo, el Centro Nacional de Ingenieros lo hizo en 1895 y el Colegio de Abogados, recién en 1913. Véase Di Stéfano, R.; Sábato, H.; Romero, L. A. y Moreno, J. L: De las cofradías a las organizaciones de la sociedad civil. Historia de la iniciativa asociativa en la Argentina, Gadis, Buenos Aires, 2002, págs. 121- 123 y 156-160. Sobre la Asociación Médica,véase González Leandri, Curar, persuadir..., págs. 30-33. Goyena.

11 Dicha entidad editó además la Revista Literaria Argentina, dirigida por J. M. Estrada y P.

12 También se fundó en la misma época la Junta de Historia y Numismática que desde 1923 pasaría a ser la Academia Nacional de la Historia.

13 Giusti, R.: Momentos y aspectos de la cultura argentina, Raigal, Buenos Aires, 1954, pág. 54 y ss. El papel del Ateneo en el desarrollo de las artes plásticas ha sido abordado recientemente por Malosetti Costa, L.: Los primeros modernos. Arte y sociedad en Buenos aires a fines del siglo XIX, FCE, Buenos Aires, 2001, págs. 347-404.
} 
en 1885, cargo que ocuparía hasta su muerte en 1929 (donde creó la revista La Biblioteca). ${ }^{14}$

Con todo, el carácter excepcional del hecho de que un extranjero alcanzara la autoridad intelectual que detentó Groussac revela que el panorama predominante era exactamente el opuesto ${ }^{15}$. Así, por ejemplo, si se recuerda quiénes fueron los colaboradores del primer número de $L a$ Biblioteca, encontramos personajes tales como José María Ramos Mejía, Bartolomé Mitre, Miguel Cané y Rafael Obligado. ${ }^{16}$ El Ateneo también reflejó la preeminencia de los sectores más tradicionales en las esferas intelectuales y en el mundo de la cultura de la Buenos Aires del fin de siglo. Entre sus fundadores se contaron figuras como Carlos Guido Spano, Lucio V. López, Miguel Cané, Ernesto Quesada, Lucio V. Mansilla, Calixto Oyuela o Enrique Larreta —entre otros-, todos ellos provenientes de familias de antigua raigambre en la ciudad.

Desde ya, hubo discusiones entre estos intelectuales a pesar de compartir su origen social. Entre ellos, se destacó el concerniente a cuál debía ser la arista preeminente en la formación intelectual ante los desafíos que planteaban las radicales transformaciones de la sociedad: si la denominada cultura estética o, en cambio, la llamada cultura científica, una discusión, sin embargo, entablada sobre el denominador común del rechazo a la formación profesional imperante en la universidad. ${ }^{17}$ Por otro lado, el disenso sobre el modelo de intelectual revelaba a su vez el diferente papel que estas

14 Al respecto, véase Bruno, P.: Paul Groussac. Un estratega intelectual, Universidad de San Andrés - FCE, Buenos Aires, 2004.

15 Algo similar podría plantearse para el campo académico. La Universidad de Buenos Aires anterior a las transformaciones estructurales del novecientos cobijó a profesionales extranjeros que desde allí alcanzaron lugares importantes. Veamos un ejemplo: Jorge Duclout fue un ingeniero alsaciano nacido en 1854, que llegó a la Argentina en 1884, ya graduado. Un año después de arribar al país ya era profesor de la Facultad de Ciencias Exactas de la Universidad de Buenos Aires. Años después fue presidente de la Sociedad Científica Argentina. Asimismo, fue integrante del Departamento de Ingenieros del Ministerio de Obras Públicas, siendo así activo protagonista de las tareas de modernización de la infraestructura de servicios del país (como el trazado de ferrocarriles, canales, etc). Su biografía registra cómo un saber especializado podía brindar a un recién llegado la promoción hacia cargos públicos en la Argentina de fin de siglo, pero también que su inserción profesional en el país fue a través de una facultad menos vinculada a la elite tradicional, a diferencia de la de Derecho (y en menor medida, la de Medicina). Los datos biográficos de Duclout, extraídos de Piccirili R. y otros: Diccionario histórico argentino, Ediciones Historias Argentinas, Buenos Aires, 1953.

16 Lafleur, H. y otros: Las revistas literarias argentinas 1893-1967, CEAL, Buenos Aires, 1968, pág. 23.

17 Cané (y Groussac) adhirieron a la primera posición, mientras que Quesada fue exponente de la segunda. Véase Terán, O.: Vida intelectual en el Buenos Aires fin-de-siglo (1880-1910). Derivas de la “cultura científica”, FCE, Buenos Aires, 2000, págs. 277-287. 
ocupaciones tenían en cada trayectoria individual. Así, por ejemplo, para algunos (como Groussac), la insistencia en la necesidad de avanzar en la especialización de las letras y las humanidades era el corolario, en buena medida, haber construido su lugar en la sociedad gracias a ellas, mientras que para otros, provenientes de familias más tradicionales (como Miguel Cané, por ejemplo), las inclinaciones espirituales eran una forma de recortar su singularidad en la elite social a la que ya pertenecía por factores adscriptos, lo cual probablemente subyaciera al diletantismo que encarnó y defendión ${ }^{18}$.

Pero, por debajo de estos matices, la condición de intelectual era una forma de construir una identidad social distinguida, que servía como eje de diferenciación no sólo del resto de la sociedad sino también en el interior de las altas esferas. El carácter excepcional del hombre de ideas subyace a la extendida noción de concebirse como una "aristocracia intelectual", señala también las influencias de la época, en especial de autores franceses como Renan o Taine. Como le escribiera Groussac a Cané, "el odio al espíritu" era el "odio general por toda aristocracia". ${ }^{19}$

Justamente, esta identificación recíproca anclada en una concepción de la superioridad de las inclinaciones intelectuales o espirituales - que al mismo tiempo fraguaba un reconocimiento de pertenencia mutua entre individuos de diferentes backgrounds, como los propios Cané y Groussac - se tejía por medio de las sociabilidades intelectuales, como lo marcaron los propios protagonistas: "Nos considerábamos iguales porque nos considerábamos superiores, y en nuestra categoría de soberanos, no cabían cuestiones de présence" ${ }^{20}$ De esta manera, se distinguían del vulgo, pero también del "vulgo distinguido", ${ }^{21}$ siendo los cenáculos literarios, académicos y/o científicos los motores con los que se modelaban estas identidades.

En consecuencia, si retrospectivamente los intelectuales y hombres de letras de la alta sociedad porteña pueden calificarse como gentlemen escritores, para apelar a una descripción que ilustra tanto su extracción social como su carácter aún poco profesional, vale subrayar dos puntos: por un

18 Véase Bruno, Paul Groussac...; Losada, L.: "Miguel Cané: Diletantismo, política y alta sociedad en la Buenos Aires del novecientos", en Echeverría, O. y Pasolini, R. (comps.): Entre notables y desconocidos. Biografía e Historia en la Argentina del siglo XX, IEHS, Tandil (en prensa).

19 AGN, S. VII, Fondo Cané, 2200. P. Groussac a M. Cané, 13 de mayo de 1898. Literario).

20 García Merou, Recuerdos literarios..., págs. 56-57 (pasaje referido al Círculo Científico

21 Expresión de Miguel Cané, referida por Sáenz Hayes, R.: Miguel Cané y su tiempo (18511905), Kraft, Buenos Aires, 1955, pág. 110. 
lado, que a pesar del diletantismo preeminente, los gentlemen escritores fueron pioneros en desandar el largo y sinuoso camino conducente a la profesionalización del campo intelectual, a través de las entidades que crearon (como el Ateneo). Por otra parte, debe tenerse en cuenta que su cualidad de "escritores" servía como elemento distintivo dentro del grupo más amplio de gentlemen, con el que interactuaban en los clubes sociales distinguidos de la ciudad, como el Club del Progreso, el Círculo de Armas o el Jockey Club. Esto es, que pertenecieran a los círculos tradicionales de la ciudad no debería ocultar sus conflictos internos, en relación con las sensibilidades y con las aficiones culturales e intelectuales. ${ }^{22}$

En efecto, el mundo de los intelectuales de la elite tradicional no se agotó en los espacios que congregaban a su grupo de origen como tal, es decir, a las sociabilidades de high life. Junto a los clubes distinguidos, estos individuos circularon y conformaron sociedades, dedicadas específicamente a las inquietudes e intereses culturales, corporativo-profesionales, etc., con las que forjaron una identidad de distinción en el entramado de sus pares sociales.

Pero a la vez, los ámbitos intelectuales los contactaron con gente que provenía de una extracción social bien diferente, sobre todo a medida que la movilidad social y el impacto inmigratorio fueron cobrando importancia en la Buenos Aires del cambio de siglo. En el mundillo de escritores y de artistas, así como en la propia Universidad (UBA) comenzó a ingresar una creciente heterogeneidad desde los últimos años del XIX. La cantidad de alumnos de la UBA, por ejemplo, aumentó de forma significativa a lo largo del período: pasó de 963 estudiantes en 1889 a 4000 para principios de siglo, un crecimiento que no se debió sólo a las nuevas unidades académicas que fueron surgiendo (Filosofía y Letras en 1896; Agronomía y Veterinaria en 1909; Ciencias Económicas en 1913), sino también al que experimentaron las carreras más tradicionales como Derecho o Medicina. ${ }^{23}$

22 Al respecto, véase Losada, L.: Distinción y legitimidad. Esplendor y ocaso de la elite social en la Buenos Aires de la belle époque, tesis de doctorado, UNCPBA, Tandil, Buenos Aires, 2005, cap. VII. La expresión gentleman escritores pertenece a Viñas, D.: Literatura argentina y realidad política, CEAL, Buenos Aires, 1982. Sobre los clubes sociales de este período, véase Edsall, T. M.: Elites, Oligarchs and Aristocrats: The Jockey Club of Buenos Aires and the Argentine Upper Classes, 19201940, Ph. Diss, Tulane University, 1999; Gálvez, L.: Club del Progreso. La sociedad, los hombres, las ideas. 1852-2000, Buenos Aires, 1999; Círculo de Armas: En el centenario de su fundación, Buenos Aires, 1985.

23 Chiroleu, A.: "La reforma universitaria", en Falcón, R. (dir.): Nueva Historia Argentina, T. VI: Democracia, conflicto social y renovación de ideas, 1916-1930, Sudamericana, Buenos Aires, 2000, pág. 368 . 
La recomposición social no se limitó al alumnado, también alcanzó al profesorado - sobre todo en Filosofía y Letras—; queda demostrado entonces que en Buenos Aires la reforma de 1918 fue más bien el emergente de una serie de mutaciones que fueron produciéndose desde los primeros años del siglo XX que el punto de partida de un proceso de renovación. ${ }^{24}$ Por su parte, la revista Nosotros, un espacio central en el sendero orientado a la profesionalización de las letras, tuvo como uno de sus fundadores a Roberto Giusti, nacido en Luca, Italia, en 1887, y llegado a la Argentina en su infancia, en 1895. En sus memorias dejó pasajes elocuentes sobre la permeabilidad de la estructura social de la Buenos Aires de la época, del ascenso y de la renovación de la sociedad que sobre ella generó el fenómeno inmigratorio, e incluso de la ausencia —o al menos, de la debilidad — de las barreras interpuestas por los sectores tradicionales:

\footnotetext{
"Han propalado una enorme mentira los que vociferaron que en la Argentina de ayer nadie podía estudiar ni llegar a ser algo sin poseer fortuna pecuniaria o apellido de alcurnia. Soy un ejemplo entre miles de los muchachos sin fortuna pecuniaria $[\ldots]$ a quienes nada ni nadie cerró el paso.”25
}

En otras palabras, las esferas intelectuales fueron exponentes nítidos de las transformaciones que sufrió la sociedad y las que posibilitaron que los integrantes de los círculos tradicionales y los hombres nuevos aparecidos al compás del boom inmigratorio comenzaran a tener una convivencia íntima o al menos, frecuente. En este sentido, cabe destacar que la tutela o el padrinazgo de los hombres de la high society fue por entonces un capital importante para tener éxito en estos terrenos o al menos para construir una carrera en la Buenos Aires del novecientos. De este modo, por ejemplo, la revista Nosotros contó con el mecenazgo de Rafael Obligado, uno de los máximos exponentes de la poesía gauchesca y miembro de una acendrada familia porteña. En cuanto a las trayectorias individuales, cabe mencionar el apoyo que otro escritor inmigrante, el español Francisco Grandmontagne (autor de uno de los clásicos de este período, Teodoro

24 Al respecto, véase Halperín, Donghi: Historia de la Universidad...; Buchbinder, Historia de la Facultad... Véase también Ciria, A. y Sanguinetti, H.: La reforma universitaria, CEAL, Buenos Aires, 1983, págs. 239-279; Tedesco, J. C.: "La universidad y su reforma", en Romero, J. L. y Romero, L. A.: Buenos Aires. Historia de cuatro siglos, Abril, Buenos Aires, 1983, t. II.

25 Giusti, R.: Visto y vivido. Anécdotas, semblanzas, confesiones y batallas, Buenos Aires, 1965, pág. 24. 
Foronda, que justamente lleva a la ficción las esperanzas de ascenso social a través de la educación universitaria), recibió de Miguel Cané. ${ }^{26}$ También es ilustrativa la relación que vinculó a José María Ramos Mejía, uno de los intelectuales más importantes del cambio de siglo (autor de ensayos sociológicos claves de la época, como Rosas y su tiempo o Las multitudes argentinas), también proveniente de una tradicional familia porteña, con José Ingenieros, otro hijo de inmigrantes que ocuparía un lugar igualmente relevante en la intelectualidad de la belle époque. ${ }^{27}$ En efecto, Ramos Mejía fue un padrino crucial en la carrera de Ingenieros al darle un lugar en el Departamento Nacional de Higiene cuando ocupó la presidencia de dicho organismo. ${ }^{28} \mathrm{~A}$ su vez, su relación revela las lábiles fronteras que por entonces existían entre la cultura científica y la cultura estética. Ramos Mejía alternó con los jóvenes poetas modernistas — con quienes también se relacionaba Ingenieros - centrados alrededor del nicaragüense Rubén Darío -quien llegó a Buenos Aires en 1896-, gracias a que el bibliotecario del Departamento Nacional de Higiene, Eugenio Díaz Romero, era también el editor de El Mercurio de América, la revista del grupo modernista ${ }^{29}$.

En consecuencia, en una sociedad porosa, el mundo cultural no fue una excepción. Con todo, a pesar de la convivencia y de la mixtura crecientes, en los años del cambio de siglo, el papel central y la autoridad intelectual aún eran detentados por los hombres provenientes del alto mundo social porteño, o al menos aquellos que se habían insertado y familiarizado con él antes de las transformaciones estructurales aceleradas en la década de 1880. En el terreno de las letras, la unción de un Miguel Cané o de un Paul Groussac era una carta segura de reconocimiento, como lo revela la valoración dada a sus juicios positivos sobre la obra de algún intelectual, según se aprecia al reco-

26 Véase al respecto, Saénz Hayes, Miguel Cané..., págs. 372-375. Las oportunidades abiertas por la educación para el ascenso y la respetabilidad, temas del citado libro de Grandmontagne, se recortan como un tópico reiterado en la literatura y el teatro de la época. El ejemplo más emblemático es F. Sánchez, M’ hijo el doctor. Véase Teatro de Florencio Sánchez, Sopena Argentina, Buenos Aires, 1942.

27 Sobre J. M. Ramos Mejía véase Clementi, H.: "José M. Ramos Mejía”, en Biagini, H. (comp.): El movimiento positivista argentino, Belgrano, Buenos Aires, 1985; sobre J. Ingenieros, véase Terán, O.: José Ingenieros. Pensar la nación, Alianza, Buenos Aires, 1986.

28 Con relación a su papel en esta institución, véase González Leandri, R.: "Madurez y poder. Médicos e instituciones sanitarias en la Argentina a fines del siglo XIX", en Entrepasados, 27, XIV, 2005, págs. 142-144; González Leandri, R.: "El Consejo Nacional de Higiene y la consolidación de una elite profesional al servicio del Estado. Argentina 1880-1900”, en Anuario de Estudios Americanos, LXI-2, Sevilla, 2004.

29 Salessi, J: Médicos, maleantes y maricas. Higiene, criminología y homosexualidad en la construcción de la nación Argentina (Buenos Aires: 1871-1914), Beatriz Viterbo, Buenos Aires, 1995, págs. 133-137. 
rrer su correspondencia privada. ${ }^{30}$ Después de todo, Manuel Gálvez (sobre quien volveremos más adelante) y Roberto Giusti, que en sus memorias no dudan en presentarse como responsables sobresalientes de la afirmación del campo intelectual en la Buenos Aires del novecientos en tanto que impulsores de revistas como Ideas y Nosotros (respectivamente), reconocen también las moderadas rupturas que la acompañaron (coinciden en que las más sensibles llegaron con las “modernas" vanguardias de la década de 1920, centradas alrededor de publicaciones como Prisma, Proa y Martín Fierro). Una demostración cabal al respecto fue el artículo que Alberto Gerchunoff - literato de ascendencia judía, autor de una de las novelas clásicas de las letras argentinas de comienzos del siglo XX, Los gauchos judios- escribió al morir Cané: “¡Al fin solos!”. Además de ser definido retrospectivamente por Gálvez como una muestra de las irreverencias juveniles de su generación, es un indicio de la centralidad de los gentlemen escritores en el por entonces aún incipiente campo intelectual. ${ }^{31}$

Sin embargo, su protagonismo se iría atenuando en el transcurso de las primeras décadas del siglo XX. En efecto, la paulatina profesionalización de las actividades intelectuales culminaría erosionando la relevancia de los vínculos con la elite porteña tradicional, al opacar el lugar de su mundo como espacio social clave para la construcción de éxito, prestigio y legitimidad. Al mismo tiempo la preponderancia de los intelectuales provenientes de aquel círculo social también fue menguando a medida que los inmigrantes se hacían notar y aumentaban en número.

\section{El mundo intelectual durante las primeras décadas del siglo $\mathrm{XX}$}

Un somero repaso del vínculo que destacados intelectuales de los años 1910 (como Leopoldo Lugones, José Ingenieros o Ricardo Rojas) guardaron con la elite porteña tradicional nos muestra cómo fue merman-

30 Con relación a Cané, véase AGN, S. VII, Fondo Cané, 2200. C. Oyuela a M. Cané, 1 de febrero de 1905; G. de Laferrere a M. Cané, junio 1904, ibídem; M. Montes de Oca a Cané, 14 de abril de 1901, ibídem; AGN, S. VII, Fondo Cané, 2199. R. Cárcano a M. Cané, 6 de marzo de 1904. Con relación a Groussac, véase AGN, S. VII, Fondo Groussac, 3015. E. Larreta a P. Groussac, 12 de octubre de 1903, 14 de enero de 1907, 27 de abril de 1907, M. Láinez a P. Groussac, 6 de julio de 1883 (donde Láinez destaca el "capital de su talento" al francés), L. López a P. Groussac, 8 de febrero de 1884.

31 Gálvez, M.: Amigos y maestros de mi juventud, Hachette, Buenos Aires, 1961, pág. 71; Gálvez, M.: En el mundo de los seres ficticios, Hachette, Buenos Aires, 1961, pág. 241; Giusti, Visto y vivido..., págs. 79-99. 
do la relevancia de este sector en la dinámica del campo cultural y, en consecuencia, cómo se desdibujó la necesidad de pertenecer o ingresar a ella para obtener reputación intelectual. Los casos mencionados son justamente sugestivos porque sus vínculos con la alta sociedad, si bien no fueron nunca demasiado íntimos, sí reconocieron en un primer momento, en el comienzo de sus carreras, el favor de las cooptaciones "meritócráticas" que aquella operó durante la belle époque. ${ }^{32}$

La trayectoria y los perfiles que José Ingenieros construyó de sí mismo como intelectual nos revelan de manera sugestiva el apogeo y el eclipse progresivo de la alta sociedad porteña como referencia en el campo cultural.

La promoción de Ingenieros encontró una de sus cifras en las tutelas y mecenazgos del orden conservador, como lo demuestra su ya señalada relación con José María Ramos Mejía. En su caso, además, los vínculos anudados en las sociabilidades intelectuales le permitieron crear una genealogía de pertenencia a los círculos tradicionales de Buenos Aires, a él, que era un hijo de inmigrantes: "meditando sobre este sentimiento de repulsión hacia los ignorantes ensoberbecidos por el dinero o la política, he podido advertir que si a Ramos Mejía se lo contagió López, a mí me lo contagió Ramos Mejía". ${ }^{33}$ La identificación tejida con los intelectuales provenientes de las familias tradicionales, construida sobre la base de una sensibilidad compartida derivada de su condición como intelectual, opacaba así las diferencias que existían entre López, Ramos Mejía e Ingenieros en lo referido a sus extracciones sociales. En otras palabras, si para aquellos que provenían de las familias tradicionales, las sociabilidades intelectuales sirvieron para forjar una noción de distinción inter pares, para quienes convivían con ellos en dichos cenáculos y poseían orígenes sociales "nuevos" éstas aparecían como espacios idóneos para trazar un lazo de pertenencia con la alta sociedad. En verdad, Ingenieros parece haber perseguido con afán, al menos hasta mediados de los años diez, el acceso al gran mundo porteño: trascender el vínculo meramente intelectual o profesional con integrantes de la high society para obtener una consideración como un par más propiamente social. Semejante interés devela, en este sentido, la centralidad que jugaba el círculo social del que provenían figuras como López y Ramos Mejía en la Argentina del novecientos. Así, en distintas evocaciones y sem-

32 La expresión es de Halperín Donghi, T.: Vida y muerte de la República Verdadera, Ariel, Buenos Aires, 1999.

33 Ingenieros, J.: "La personalidad intelectual de José M. Ramos Mejía", en Salessi, Médicos..., pág. 147. 
blanzas realizadas sobre Ingenieros, se lo describe casi como un advenedizo de origen inmigratorio: alguien que cambia su apellido para disimular su procedencia (Ingenieros por Ingegnieros); un personaje que viste de manera llamativa, antes que sutil; una personalidad cuyas aficiones, entre las que se destacaba la de hacer bromas pesadas, lo alejaban del clubman distinguido y mesurado en maneras y comportamientos. ${ }^{34}$ Semejantes conductas obligan a pensar si, más que un supuesto afán de admisión, no había en ellas, en realidad, una forma de parodiar las prácticas imperantes en el gran mundo porteño, con el desdén propio que un aristócrata del espíritu demostraría por las cuestiones de présence. Desde ya, el interrogante sobre las motivaciones que latieron detrás de las conductas de Ingenieros probablemente nunca pueda responderse sino a través de la conjetura. Lo que sí vale resaltar es que su integración al alto mundo porteño distó de ser incompleta, y lejos estuvo de ser considerado como un simple perseguidor de reconocimiento. En sus páginas recién citadas, César Viale, figura relevante en espacios como el Jockey Club y el Círculo de Armas, señaló en sus recuerdos los almuerzos que Ingenieros ya no presidía en La Syringa (el núcleo modernista de Rubén Darío) sino en el Jockey Club. En palabras de Viale, en la alta sociedad se consideraba que "conocer y tratar a Ingenieros era un título en aquel tiempo." 35

Por lo tanto, más allá de su éxito o de sus motivaciones, la trayectoria de Ingenieros muestra que la elite porteña era, al menos hasta el ocaso de la belle époque de preguerra, un núcleo gravitante que contribuía a la edificación de prestigio personal, tanto como intelectual como, en un sentido amplio, más cabalmente social. Pero a la vez, las identidades y las referencias asumidas por Ingenieros también nos ilustran los recambios de legitimaciones producidos desde entonces.

Así se advierte su perfil de la posguerra: sobresale su autoproclamado carácter de líder de la juventud, su adhesión al bolchevismo, la conjugación de ambas aristas en una perspectiva latinoamericana embanderada en la justicia social y sostenida en la nueva generación, como lo expresó el programa de la revista Renovación, que ideara e impulsara.$^{36}$ Es claro que, otra

34 Véase Gálvez, Amigos y maestros..., pág. 135 y ss; Viale, C.: Estampas de mi tiempo, Casa editora Julio Suárez, Buenos Aires, 1945, pág. 162 y siguientes.

35 Viale, Estampas..., págs. 163-164. De acuerdo con la base de datos del Jockey Club, José Ingenieros (contra lo que en general se afirma) aparece como socio entre 1907 y 1925 (año de su muerte). Agradezco este dato al Sr. Roberto Müller, director de la Biblioteca de esa institución.

36 El programa de Renovación, citado en Lefleur, Las revistas..., pág. 118. 
vez, se abre el campo a las presunciones para pensar por qué Ingenieros cambió tan sensiblemente su perfil como intelectual entre el comienzo del siglo y la posguerra. Se puede recurrir a los móviles atribuidos por Manuel Gálvez (sin dudas simplistas, y en los que también late cierta antipatía, que se intuye detrás de las declaraciones de afecto y de respeto): un Ingenieros despechado social y académicamente (esto último luego de que el presidente Roque Sáenz Peña vetara su nombramiento en una cátedra de la Facultad de Medicina) y que, frente a ello, luego de sus coqueteos con la alta sociedad y con la dirigencia política del conservadurismo, "regresó" a sus orígenes. ${ }^{37} \mathrm{O}$, por otro lado, también se puede pensar en una búsqueda de mantener visibilidad intelectual, ante las recusaciones al positivismo que se sucedieron con el cambio en el clima de ideas de la posguerra - vale recordar que Ingenieros había sido uno de sus máximos exponentes en el pensamiento argentino del novecientos-, y en un terreno más concreto y personal, frente al revés académico sufrido al perder el decanato de la facultad de Filosofía y Letras en 1918. Todo ello, claro está, sin dejar de considerar sinceras sensibilidades e inquietudes.

De todas maneras, en la segunda mitad de la década del '10, Ingenieros construyó su lugar como intelectual desde un nuevo punto de vista que exponía los recambios sucedidos desde entonces, y las nuevas vías de consagración o de legitimidad a que podían apelarse en el ocaso del régimen conservador, de la democratización de la política y de la reforma universitaria de 1918. Lo interesante es que el Ingenieros "juvenilista" e izquierdista de la posguerra, tan alejado del positivista del novecientos que flirteara con el alto mundo porteño, dio pie para que de él se trazaran semblanzas recíprocamente antagónicas, en las cuales los rasgos que fueran objeto de descalificación de acuerdo con los parámetros de la alta sociedad adquieren apreciaciones positivas. Así sucede con el Ingenieros que evoca Roberto Giusti: el que si hubiera tenido riqueza, la habría volcado a su compromiso con la "cultura libre", expresada por lo demás en su empresa editorial, La Cultura Argentina; el guía espiritual de la juventud; el sabio dedicado al trabajo durante largas horas en las noches (tan aleja-

37 Esta alusión de Gálvez se debe al pasado juvenil de Ingenieros, que en los últimos años del siglo XIX había sido redactor de la revista de tendencia anarquista La Montaña. Por otro lado, se ha señalado recurrentemente que El hombre mediocre — uno de sus libros de mayor trascendencia- se inspiró en Roque Sáenz Peña. Incluso el propio Gálvez apunta que Ingenieros exclamó, ante el numeroso cortejo fúnebre del presidente (fallecido en 1913), “¡Cuánta gente que no ha leído mi libro!”. Con todo, T. Halperín Donghi ha precisado que ese texto es anterior a la denegación de la cátedra universitaria. Gálvez, Amigos y maestros..., pág. 148; Halperín, Vida y muerte..., pág. 61. 
do del ocioso diletante); pero también aquel que ya no aparece frecuentando el Jockey sino los almuerzos de la revista Nosotros, incluso el mismo que en esas oportunidades "solía elegir los platos simples y sustanciosos y desdeñaba las exquisiteces culinarias" ${ }^{38}$. Fueren cuales fuesen sus motivaciones, entonces, el contraste entre el Ingenieros pre y post 1916 alumbra la importancia y luego el posterior ocaso de la significación de tomar como modelo la alta sociedad - $\mathrm{O}$ al menos en su mundo socio culturalpara construir una imagen reputada y respetable en la Buenos Aires de posguerra.

Para Ricardo Rojas, en tanto, el favor de destacados personajes de la alta sociedad porteña, en su caso Pellegrini, había sido tan importante en los comienzos de su trayectoria intelectual como lo había sido el padrinazgo de Ramos Mejía para Ingenieros; ${ }^{39}$ a pesar de sus diferentes orígenes sociales. Rojas, nacido en Tucumán, provenía de una de las familias políticamente más fuertes del Santiago del Estero de fin de siglo (su padre había sido gobernador de la provincia en 1880). Sin embargo, Rojas no tuvo un vínculo íntimo con el mundo social de la high society. Así, recién ingresó al Jockey Club en 1921, y como reconocimiento a la conferencia que allí dio sobre Pellegrini (el fundador del club), con motivo de la inauguración de la sala de la biblioteca de dicha entidad. En esa oportunidad, incluso, Rojas trazó un claro distanciamiento con la institución:

"No pude convencer a los caballeros, que me honraban al solicitar mi palabra, sobre el desacierto de mi elección; y a ellos les fue muy fácil seducirme cuando invocaron las excepcionales circunstancias del acto a que asistimos." ${ }^{\prime 4}$

Las aristas políticas de comienzos de los años veinte sin duda incidieron para que Rojas planteara esa sutil toma de distancia (concurrir más por respeto a la figura de Pellegrini que por la empatía con la institución que le había hecho el convite). Aun cuando en el Jockey convivieron conservadores y radicales (la gran división de la política argentina luego de la elección de Hipólito Yrigoyen en 1916, que puso fin a treinta y seis años de hegemonía de las elites conservadoras), los primeros predominaron sobre los segundos en sus cúpulas dirigentes durante la década del veinte (aún más,

38 Giusti, Visto y vivido..., págs. 107-111.

39 Véase Devoto, F.: Nacionalismo, fascismo y tradicionalismo en la Argentina moderna. Una historia, Siglo XXI, Buenos Aires, 2002, pág. 81.

40 La Nación, 23 de junio de 1921. 
el Jockey fue ámbito de reunión y de preparación del golpe de Estado que depuso a Yrigoyen de su segunda presidencia, en 1930). ${ }^{41}$ Rojas, en cambio, adhirió al radicalismo y a causas apoyadas por el presidente Yrigoyen. Fue así el autopostulado líder de la juventud durante la Reforma universitaria de 1918 (como lo plasmó en su Profesión de fe de la nueva generación, de 1923), el rector emblemático de la reformada Universidad de Buenos Aires de los años veinte y uno de los intelectuales más importantes de la época identificado con la Unión Cívica Radical. En última instancia, sus creencias políticas culminaron distanciándolo de la sociabilidad de la upper class: en 1936 se le solicitó la renuncia al Jockey alegando que no participaba de la vida de club, argumento detrás del cual parecía estar implícito, sin embargo, su compromiso con la causa radical y el encarcelamiento sufrido a causa de éste ${ }^{42}$.

Al igual que en el caso de Ingenieros (si bien desde posiciones políticamente más moderadas), las referencias y las identificaciones que Rojas asumió a partir de la segunda mitad de los años diez develan que la unción de la alta sociedad no era un capital necesario para obtener reconocimiento o prestigio, por efecto de que al compás de la democratización acelerada desde entonces, las instancias para conseguirlo se habían diversificado y ampliado (y en este sentido, incluso, la desacreditación de la high society podía ser un capital a favor antes que en contra). Pero más allá de esto, vale subrayar otro punto: si Rojas había encontrado en el mecenazgo de figuras de la alta sociedad y de la elite política del novecientos un sostén fundamental para construir su trayectoria como intelectual, la necesidad de ingresar más íntimamente a su mundo social no fue igualmente relevante. Antes bien, su admisión al Jockey Club en 1921, no fue un hito significativo en la edificación de su carrera, sino que tuvo lugar cuando ya era uno de los intelectuales de mayor peso de la Argentina, y cuando los posicionamientos que lo revalidaron como tal se anclaban en referencias claramente alejadas - por no decir contrapuestas - a las imperantes en una proporción mayoritaria de la alta sociedad.

La trayectoria de Leopoldo Lugones, por su parte, otro de los más importantes intelectuales de la Argentina de las primeras décadas del siglo XX, y compañero de juventud de Ingenieros (en la revista La montaña),

41 Devoto, Nacionalismo, fascismo..., págs. 241-248. Sobre las tendencias políticas en el Jockey Club, Edsall, véase Elites..., págs. 103-126.

42 Agradezco nuevamente esta referencia al Sr. Roberto Müller. 
refleja aún mejor el cambio que estamos analizando. A diferencia de Ingenieros y de Rojas, Lugones se destacó en el terreno de las letras antes que en el de la ciencia o el campo académico. A su vez, también en contraste con el autor de El hombre mediocre, provenía de una familia cordobesa de antigua raigambre en el país, aunque al mismo tiempo carente de la gravitación que había tenido la de Rojas. Por ello, las cooptaciones "meritocráticas" del orden conservador —en este caso, los vínculos que algunos de sus familiares tenían con el roquismo— ${ }^{43}$ fueron también claves en su carrera, porque le permitieron ingresar al diario La Nación, el principal medio de prensa de Buenos Aires en el cambio de siglo. Su peculiar extracción social (provenir de una familia de abolengo sin fortuna) fue resaltada por un contemporáneo en ocasión de su encuentro con Roca en La Nación, al subrayarse su "tosquedad hidalga"

A pesar de estos juicios peyorativos, Lugones se dio a sí mismo un lugar autónomo de la elite tradicional, aun cuando - a diferencia de Rojas - coincidió o, mejor aún, pretendió ejercer cierto adoctrinamiento ideológico-político sobre este círculo social durante los años veinte. No obstante, sus vínculos nunca fueron más allá de lo intelectual, es decir, de ofrecer conferencias en los ámbitos de la sociabilidad distinguida o para el público selecto de la alta sociedad (como las que dio en el Teatro Odeón en los años diez, o ya en los veinte, en la Liga Patriótica o en el mismo Jockey Club, una entidad de la que nunca fue socio). Lo cierto es que fuera a causa de su peculiar origen social o del marcado individualismo que se ha subrayado como rasgo destacado de una personalidad, no existen testimonios claros que den cuenta de un interés por parte del poeta cordobés de codearse con la "canalla enguantada" que refiriera a Rubén Darío, de ingresar en ese universo más allá de los beneficios que pudiera reportarle en su carrera como intelectual ${ }^{45}$. Como lo marca en la edición de sus conferencias del Odeón de 1913, célebres por consagrar al Martín Fierro como poema épico nacional y al gaucho como símbolo de la tradición argentina, guardó de presentar una relación de distancia, en la que a la vez resaltó que, antes que recibir una consagración de parte de su auditorio, él era el poeta "enunciador de verdades". ${ }^{46}$

43 Véase Devoto, Nacionalismo..., págs. 77-82.

44 Citado en Viñas, Literatura argentina..., págs. 255-257.

45 Carta a Rubén Darío de 1896, citada en Conil Paz, A.: Leopoldo Lugones, Huemul, Buenos Aires, 1985, pág. 185.

46 Véase Lugones, El payador (1916), Huemul, Buenos Aires, 1972, pág. 36 y ss. 
Por lo tanto, es atractivo pensar que Lugones muestra la paulatina marginalidad de la elite porteña en la construcción del prestigio o en la erosión de la figura del intelectual. Aun cuando varios momentos importantes de su trayectoria (como las citadas conferencias del Odeón de 1913) estuvieron relacionados con la consagración que ofrecía la "canalla" que dijera despreciar, su figura como intelectual y su lugar en el campo cultural y literario ya en los años veinte dependió más de su vínculo con la vanguardia de la revista Martín Fierro, esto es, de intelectuales y literatos en todo caso cercanos a la elite porteña, antes que con la elite porteña en su conjunto y como grupo social. ${ }^{47}$

Manuel Gálvez —otro hombre de letras que había asomado hacia 1910, con la publicación de El diario de Gabriel Quiroga - representa otra modalidad de consagración que se abre en las primeras décadas del siglo XX: la obtenida a través del mercado. ${ }^{48}$ En efecto, Gálvez ilustra cómo, poco a poco, el nombre literario ya no emergió exclusiva o incluso preponderantemente del reconocimiento dado "entre nos", apelando a la ilustrativa expresión con que Lucio V. Mansilla delimitaba el círculo de los potenciales lectores de sus causeries en los años $1880^{49}$. Como el propio Gálvez lo remarca en reiterados pasajes de sus memorias, hacia 1910, el prestigio literario podía resultar del éxito en un mercado editorial que, gracias a la reducción del analfabetismo, la extensión social de la educación y la prosperidad material que amplió el horizonte de los consumos culturales entre los sectores populares de la Buenos Aires de comienzos del siglo XX, superaba ya las fronteras de los pares sociales..$^{50} \mathrm{~A}$ propósito, vale recordar

47 Véase Sarlo, B.: "Vanguardia y criollismo: la aventura de "Martín Fierro"” en Sarlo y Altamirano, Ensayos argentinos... Con relación a su pretendido adoctrinamiento político e ideológico sobre la alta sociedad — con una prédica antidemocrática y en ocasiones, de tonos fascistas-, últimamente se ha matizado su grado de influencia, precisándose que en todo caso tuvo cierta importancia sobre personajes puntuales - aunque de crucial protagonismo en la política argentina de fines de los años veinte-, como el general José F. Uriburu, cabecilla del golpe de Estado contra Yrigoyen en 1930. Véase al respecto Devoto, Nacionalismo..., págs. 235-278.

48 Sobre el crecimiento del mercado de consumo en este período, véase Rocchi, F.: "Inventando la soberanía del consumidor: publicidad, privacidad y revolución del mercado en Argentina, 18601940”, en Devoto, F. y Madero, M.: Historia de la vida privada: La Argentina plural, 1870-1930 Taurus, Buenos Aires, 1999, t. II; Devoto, F. y Madero, M.: "Consumir es un placer: la industria y la expansión de la demanda en Buenos Aires a la vuelta del siglo pasado", en DE, 37, 148, 1998.

49 Véase Mansilla, L.V.: Entre nos. Causeries de los jueves, El Elefante Blanco, Buenos Aires, 2000.

50 En este sentido, un caso similar fue el de Enrique Larreta, otro descendiente de las familias tradicionales porteñas, autor de novelas como Zogoibi o La gloria de Don Ramiro. De manera significativa, Gálvez traza las correspondencias entre ambos en sus evocaciones autobiográficas. Véase En el mundo de los seres ficticios, págs. 223-224. 
que el vínculo de Gálvez con la alta sociedad porteña fue más estrecho que el de otros intelectuales provincianos destacados del Centenario, como Rojas o Lugones (aunque su procedencia estaba más próxima a la del primero que a la del segundo: Gálvez pertenecía a una familia políticamente gravitante de la provincia de Santa Fe). En efecto, a diferencia de aquéllos, concertó su matrimonio con la hija de una familia de dicho círculo social, la Bunge..$^{51}$ De esta manera, el caso de Gálvez muestra cómo la consagración intelectual en la Argentina de los años diez y veinte poco podía deber a un origen o a un vínculo íntimo con la alta sociedad porteña, sino, antes bien, encontrar uno de sus pilares en una instancia que superaba los límites de ese círculo social como consecuencia de las mutaciones socioeconómicas y culturales de la época: el mercado editorial.

Pero, sin dudas, Ricardo Güiraldes es quien ilustra de manera más nítida la progresiva pérdida de peso de la alta sociedad como escenario decisivo en los arbitrajes que consagraban una reputación intelectual. Esto es así porque a diferencia de Ingenieros, Rojas, Lugones o el propio Gálvez, Güiraldes sí provenía de una familia decididamente perteneciente a la elite tradicional de Buenos Aires, propietaria de tierras en la pampa húmeda y en la que se contaban figuras destacadas de la política vernácula (como Manuel Güiraldes, socio fundador del Jockey Club, presidente de la Sociedad Rural e intendente de la ciudad de Buenos Aires entre 1908 y 1910). Y, en segundo lugar, porque su prestigio como hombre de letras no fue el resultado de su origen social o del laudo inter pares. Antes bien, éste emergió de su lugar en las disputas estéticas del campo cultural y del reconocimiento que su obra ganó en los espacios vanguardistas de la escena literaria porteña de los años veinte, que a la vez lo tuvieron como protagonista activo en publicaciones como las revistas Proa, y sobre todo, Martín Fierro. en las que obró, además, como mecenas financiero. En este sentido, resultaría erróneo señalar que la reputación intelectual de Güiraldes fue vertida por un círculo integrado por personas que podrían definirse, en sentido estricto, como sus pares sociales, pues la mayoría del grupo martinfierrista no provenía, como sí era el caso de Güiraldes, de la alta sociedad porteña. A pesar de estar integrado por destacados hombres de letras oriundos de familias tradicionales (como Oliverio Girondo, Eduardo Mallea o Jorge Luis Borges) y aun cuando esa extracción social permitiera trazar un gesto de diferenciación respecto de

51 Sobre esta familia, véase Payá, C. y Cárdenas, R.: La Argentina de los hermanos Bunge, Sudamericana, Buenos Aires, 1997. 
otros cenáculos literarios de los años veinte, ganados por una preeminencia de apellidos de origen inmigratorio (como el llamado grupo Boedo), el papel histórico y el status económico de las familias de los escritores mencionados de la revista Martín Fierro - a excepción de la de Girondo- poco podrían compararse con los de la de Güiraldes. ${ }^{52}$ En este plano, el autor del Don Segundo Sombra tenía más puntos de contacto con los gentlemen escritores de la generación del ochenta que con sus compañeros martinfierristas: es decir, una procedencia social que, a la antigüedad familiar, le sumaba una trayectoria en los primeros planos de la vida nacional.

En consecuencia, el prestigio literario de Güiraldes se fraguó en la otra esfera que, como el mercado, da cuenta de un mundo de la cultura ganado por disputas, instancias de consagración y sociabilidades propias y específicas: la aparición de las vanguardias. En este sentido, es la contracara de Gálvez, quien precisamente fue blanco recurrente de los ataques de la revista Martín Fierro. Pero detrás de este contrapunto, entonces, permanece el denominador común: Gálvez y Güiraldes, los dos intelectuales -de los referidos en estas líneas- más cercanos socialmente a la alta sociedad, fueron figuras destacadas de la escena cultural porteña de los años veinte no como resultado de una unción dada inter pares sino de la obtenida en esferas ajenas a la alta sociedad tradicional como grupo social, o al menos, indirectamente conectadas con ella (como el mercado o la vanguardia martinfierrista).

En última instancia, debemos tener presente que las propias sociabilidades intelectuales y los ámbitos sociales de la high life comenzaron a bifurcarse en el transcurso de este período: si en el fin de siglo el club era un punto de encuentro para sostener tertulias o reuniones literarias o intelectuales, durante los primeros años del siglo XX los cafés céntricos de la ciudad (como el Aue's Keller, el Royal Keller, el Richmond o el Helvetia) comenzaron a reemplazarlo. Paralelamente, fue mutando el propio perfil del intelectual: el gentleman escritor, refinado y hombre de club, dejó su lugar a la bohemia porteña. ${ }^{53}$ Estos cambios en las sociabilidades y en las identidades

52 Desde ya, vale agregar que el contrapunto entre Boedo y Florida (como se denominó también al grupo centrado alrededor de la revista Martín Fierro, a causa de que su sede quedaba en dicha calle) no se circunscribió meramente a aspectos sociológicos, sino también a los más decididamente estéticos: el realismo y la literatura comprometida con la realidad social levantada por Boedo se contrapuso al vanguardismo estético de Martín Fierro. Al respecto, Véase Sarlo, B.: "Vanguardia y criollismo", en Sarlo y Altamirano, Ensayos argentinos...

53 Véase al respecto Saldías, A.: La inolvidable bohemia porteña, Freeland, Buenos Aires, 1963; Giusti, Visto y vivido...; Echagüe, J. P.: Vida literaria, Sopena Argentina, Buenos Aires, 1941, págs. 137-155. 
se conectaban con otro: aquel que tenía lugar en la extracción social de sus protagonistas. Esto es, con la presencia cada vez más elocuente, junto a aquellos que provenían de familias tradicionales, de quienes reconocían orígenes inmigratorios. Un camino que, anunciado por la revista Nosotros en el novecientos, ejemplificó de manera emblemática el denominado grupo Boedo (contracara de los martinfierristas) en los años veinte, en el que figuraron nombres tales como Castelnuovo, Mariani, Olivari o Barletta.

\section{Líneas finales}

En este trabajo, al mirar en perspectiva la evolución del campo cultural de Buenos Aires durante las últimas décadas del siglo XIX y las tres primeras del XX, nos ha interesado subrayar, más que los cambios que se producen en ese terreno específico, los reequilibrios sociales generales que iluminan.

En este sentido, la recomposición que se produjo en el mundo intelectual - la creciente convivencia de individuos de familias tradicionales y de familias "nuevas"- fue un fenómeno sin dudas relevante pero también, en última instancia, esperable en una sociedad que cambió radicalmente como consecuencia de un fenómeno inmigratorio sin paralelos contemporáneos. Incluso, se podrían matizar estas contraposiciones, pues al comienzo y al final del período hubo figuras destacadas de una y de otra extracción, lo cual devela la porosidad característica de la sociedad porteña aún antes del boom inmigratorio. Aunque también es cierto, con relación a los hombres nuevos de uno y otro momento, que los mecanismos disponibles al comienzo para alcanzar un lugar de relevancia, de prestigio, o al menos de visibilidad, se fueron atenuando (como las cooptaciones en un principio forzosamente necesarias ante la carencia de recursos humanos en un país que requería avanzar en la institucionalización del Estado). Así, a medida que nos adentramos en el período, sus trayectorias adquirieron cada vez más los rasgos de una experiencia de ascenso social propiamente dicha (como se advierte si se compara la línea trazada que va de un Paul Groussac, pasando por un Roberto Giusti, a la de los hombres de Boedo).

Precisamente, lo que nos resulta más sugestivo es que se devela la pérdida de gravitación en la dinámica de la sociedad de la "clase alta" o las "familias tradicionales" de Buenos Aires. Esta pérdida de relevancia, vale insistir, no radica tanto en el hecho de que sus integrantes hayan perdido el 
patrimonio o la exclusividad sobre ese campo (pues, en última instancia y en sentido estricto, nunca la tuvieron durante este línea temporal), sino en el punto de que la superposición entre las sociabilidades de la alta sociedad y las sociabilidades intelectuales se fue diluyendo. Así, por ejemplo, si ingresar a un club de high life podía ser una estrategia importante en el fin de siglo para tener contacto con las figuras más gravitantes de la escena intelectual, ya no lo fue tanto a lo largo de las primeras décadas del XX. No necesariamente porque quienes frecuentaban los clubes distinguidos hubieran dejado de tener relevancia en el mapa cultural, sino porque había otras esferas ajenas al alto mundo social a través de las que se podía entablar contacto con ellos, o, directamente, desde las cuales edificar un derrotero propio.

En efecto, la profesionalización del campo intelectual, la ampliación social y la reforma institucional de la universidad, la creciente gravitación del mercado como forma de consagración literaria y el surgimiento de nuevos espacios de inserción laboral, entre los que sobresalieron los medios de prensa que aparecieron a mediados de la década de 1910, como los diarios El Mundo o sobre todo Crítica -por donde pasearían sus plumas escritores de la talla de Roberto Arlt o el propio Borges- menos vinculados a las familias tradicionales de la ciudad (como sí lo estaban los grandes diarios de hasta ese entonces, como La Prensa o La Nación), ${ }^{54}$ aparejaron novedosas formas de construcción de una carrera en el campo cultural y académico.

En este contexto, entonces, el prestigio o el éxito podía seguir decidiéndose por individuos provenientes de la elite tradicional, e incluso su mecenazgo podía ser un capital socialmente útil, pero su centralidad en el terreno intelectual no se derivaba de su procedencia, sino del reconocimiento que gozaban en el propio campo intelectual. Y éste, a diferencia de lo característico de las últimas décadas del siglo XIX, ya tenía sus epicentros en cenáculos escasamente delimitados al "entre nos", o incluso eran ajenos a la sociabilidad distinguida, sin olvidar, claro está, el papel de instancias mucho más definidamente impersonales, emergentes de los acelerados cambios económicos y sociales que había atravesado la Argentina desde entonces, como el mercado. En este sentido, por lo tanto, el campo intelectual ofrece una buena lente para descomprimir una mirada aún

54 Véase Saítta, S.: Regueros de tinta. El diario Crítica en la década de 1920, Sudamericana, Buenos Aires, 1998; Saítta, S.: "El periodismo popular en los años veinte" y Rosa, C.: "La literatura argentina durante los gobiernos radicales", en Falcón, R. (dir.): Nueva Historia..., Sudamericana, Buenos Aires, 2000, t. VI, págs. 391-471. 
vigente como representación convencional de este período de la historia argentina: aquella que plantea que una reducida elite de ascendencia criolla retuvo las riendas de la sociedad a pesar de los cambios radicales que la sacudieron. Antes bien, el panorama es bien opuesto: la diversificación de la estructura y de la lógica de la sociedad que aquellos generaron desmontaron, poco a poco pero también de manera inexorable, el mundo de la alta sociedad como un ámbito necesario de ser frecuentado (o al cual ser admitido) para construir éxito y/ o prestigio social.

Recibido el 15 de diciembre de 2005

Aceptado el 6 de abril de 2006 